\title{
РАЗДЕЛ 4.Экологическая безопастность
}

\author{
УДК 911.52 (477.75) DOI: 10.37279/2413-1873-2021-22-135-145 \\ ПРОСТРАНСТВЕННОЕ РАСПРЕДЕЛЕНИЯ НАКЛОНА ПОВЕРХНОСТИ В ПРЕДЕЛАХ \\ ЛАНДШАФТОВ КРЫМСКОГО ПОЛУОСТРОВА
}

\author{
Табунщик В.А. \\ ФГБУН ФИЦ «Институт биологии южных морей имени А. О. Ковалевского РАН», 299011, проспект Нахимова 2 , \\ Севастополь, Российская Федерация, e-mail: tabunshchyk@ ya.ru
}

\begin{abstract}
Аннотация. В работе представлены новые данные о наклоне поверхности территории Крымского полуострова в разрезе ландшафтных таксономических единиц по ландшафтно-типологической карте Крымского полуострова Г.Е. Гришанкова. Впервые для Крымского полуостров в целом и ландшафтных таксономических единиц - ландшафтных уровней, ландшафтных зон, ландшафтных поясов и ярусов, а также групп местностей (окоемов) количественно посчитаны элементы описательной статистики (минимальное значение, максимальное значение, среднее значение, медиана значений, а также значение амплитуды значений (факторной амплитуды)), которые характеризуют наклон поверхности в пределах указанных территорий.

Предмет исследования: геоморфологические особенности наклона поверхности в пределах территории Крымского полуострова, в частности ландшафтов на различных таксономических уровнях в связи со слабой проработанностью этого вопроса.

Материалы и методы. В работе использована цифровая модель рельефа SRTM на основании которой построены карты наклона поверхности для территории Крымского полуострова и ландшафтов Крымского полуострова. Обработка произведена в программном комплексе ArcGIS. B работе использованы геопространственные модели (геопривязанные растровые и векторные слои), позволяющие выполнять SQL-запросы и анализировать пространственное положение объектов исследования. Методами исследования выступают - литературно-аналитический, исторический, сравнительногеографический, геоинформационный, статистический, а также метод моделирования.

Результаты: впервые получены новые данные о значениях наклона поверхности в пределах различных иерархических уровней ландшафтной структуры Крымского полуострова.

Выводы: наклон поверхности в пределах ландшафтных контуров для территории Крымского полуострова характеризуется значительной пространственной неоднородностью - увеличивается с севера на юг и достигает максимальных значений в пределах среднегорного и низкогорного ландшафтных уровней, а минимальных - в пределах гидроморфного ландшафтного уровня.

Ключевые слова: рельеф, наклон поверхности, Крым, Крымский полуостров, ландшафт.
\end{abstract}

\section{ВВЕДЕНИЕ}

Изучение рельефа территории является одной из важнейших задач при исследовании той или иной территории. Ведь именно рельеф и его характеристики (абсолютная высота, наклон поверхности, глубина расчленения рельефа, густота расчленения рельефа и пр.) оказывают воздействие как на развитие природных, так и социальноэкономических процессов. Наклон поверхности (крутизна склонов, уклон поверхности) - это экологический фактор, который играет важную роль в распределении энергии и вещества в пределах ландшафта - интенсивность эрозионных процессов, изменение микроклиматических характеристик воздушных масс и почвы, а также при хозяйственном освоении территории. В последние годы при планировании использования территории активно применяется ландшафтный

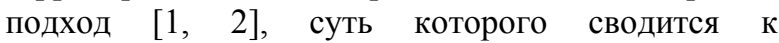
комплексному пониманию процессов и явлений природы протекающих в пределах ландшафтов [3, 4]. Именно понимание организации ландшафтов и ландшафтной сферы позволяет свести к минимуму неблагоприятные процессы, которые могут возникать при хозяйственном освоении той или иной территории.

\section{АНАЛИЗ ПУБЛИКАЦИЙ}

Изучению рельефа Крымского полуострова посвящено большое количество работ. Среди наиболее значимых стоит отметить работы А.А. Клюкина [5], П.Д. Подгородецкого [6], Б.А. Вахрушева [7], В.А. Михайлова с соавторами [8, 9], Ф.Н. Лисецкого с соавторами [10], Е.А. Позаченюк с соавторами [11], а также серии карт изданные в атласах $[12,13,14]$. Однако именно изучению рельефа в пределах различных таксономических единиц ландшафтной структуры Крымского полуострова научных работ посвящено крайне мало и, в большинстве своем, они ограничиваются лишь качественными характеристиками рельефа в пределах ландшафтов.

В тоже время сейчас наиболее целесообразно использовать дистанционные методы исследования для анализа рельефа территории. В работах многих авторов указывается, что связка и использование цифровой модели рельефа (Shuttle Radar Topography Mission (SRTM), ASTER Global Digital Elevation Map и др.) в комплексе с географическими информационными системами (ArcGIS, QGIS, SAGA GIS и др.) дают прекрасный результат для анализа рельефа и его характеристик - наклона, экспозиции, расчленения и пр. Например, в работе 
[15] с использованием ГИС и цифровых моделей рельефа исследуются отдельные бассейны рек в южной Индии; в работе [16] - в Китае; в работе [17] исследуется рельеф северной части Чили; в [18] юга Европейской части России; в работе [19] анализируется рельеф северо-восточного склона Большого Кавказа в пределах Азербайджана для целей развития туризма.

\section{МАТЕРИАЛЫ И МЕТОДЫ ИССЛЕДОВАНИЙ}

Анализ наклона поверхности проводится для операционно-территориальных единиц, представленных на ландшафтно-типологической карте Крымского полуострова Г.Е. Гришанкова [20] в разрезе таксономических единиц - ландшафтный уровень (далее - ЛУ), ландшафтная зона (далее Л3), ландшафтный пояс / ландшафтный ярус (далее - ЛП/ЛЯ), группа местностей (далее - ГМ).

Построение карты наклона поверхности или крутизны склонов производилось согласно методике, описанной в работах $[21,22]$ с использованием географических информационных систем - QGIS и ARCGIS. Для расчета показателя наклона поверхности в пределах Крымского полуострова были использованы открытые данные Shuttle Radar Topography Mission (SRTM). B результате, для территории Крымского полуострова построена карта наклона поверхности, которая в дальнейшем анализировалась с использованием алгоритмов пространственного пересечения, в результате чего для каждого ландшафтного контура и таксономической единицы получены значения описательной статистики, отражающие минимальное, максимальное, среднее значение наклона поверхности, а также медиану и амплитуду значений. Дополнительно рассчитывался показатель относительной ширины факторной амплитуды, физический смысл которого описан в работе [23].

\section{РЕЗУЛЬТАТЫ И ИХ АНАЛИЗ}

На территории Крымского полуострова (далее КП) наклон поверхности изменяется от 0 до 66,1 градуса и распределен крайне неравномерно. Наибольшие значения характерны южной части КП, где в пределах Крымских гор наблюдается значительное расчленение рельефа и большие амплитуды высот, а наименьшие характерны для Присивашской низменности на севере КП. В таблице 1 представлено распределение фактора «Наклон поверхности, градусы» по ЛУ КП.

Согласно рисунка 1, можно наблюдать, что в пределах ГЛУ наибольшее количество значений рассматриваемого показателя приходится на диапазон значений от 0 до 0,5 градуса, ПЛУ - от 0,5 до 1 градуса, НЛУ - от 0 до 2 градусов и СЛУ - от 5 до 10 градусов. Таким образом, среди ЛУ по показателю «Наклон поверхности, градусы» наиболее четко обосабливается СЛУ, в то время как остальные ЛУ - имеют незначительное разграничение по рассматриваемому фактору.

В таблице 2 и на рисунке 2 представлены характеристики ЛЗ КП в пространстве фактора «Наклон поверхности, градусы». Как можно видеть, наибольшая пространственная дифференциация характерна для ЛЗ СЛУ и НЛУ.

Таблица 1. Положение ландшафтных уровней Крымского полуострова в пространстве фактора «Наклон поверхности, градусы»

Table 1. The position of the landscape levels of the Crimean Peninsula in the factor space «Slope, degrees»

\begin{tabular}{|c|c|c|c|c|c|c|c|}
\hline \multirow[b]{2}{*}{ 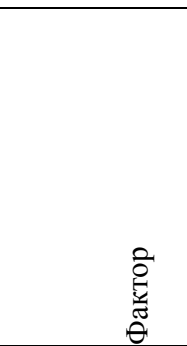 } & \multirow[b]{2}{*}{ Ландшафтный уровень } & \multicolumn{5}{|c|}{ Значение фактора } & \multirow{2}{*}{ 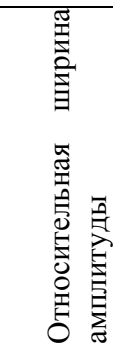 } \\
\hline & & 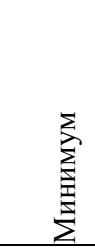 & 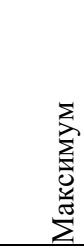 & 舀 & 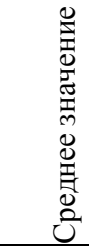 & 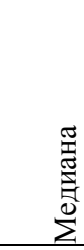 & \\
\hline \multirow{4}{*}{$\begin{array}{l}\text { Наклон } \\
\text { поверхности, } \\
\text { градусы }\end{array}$} & Гидроморфный (ГЛУ) & 0 & 21,7 & 21,7 & 0,7 & 0,5 & 0,33 \\
\hline & Плакорный (ПЛУ) & 0 & 17,5 & 17,5 & 1,0 & 0,7 & 0,27 \\
\hline & Низкогорный (НЛУ) & 0 & 66,1 & 66,1 & 4,0 & 2,0 & 1,00 \\
\hline & Среднегорный (СЛУ) & 0 & 62,0 & 62,0 & 10,9 & 9,9 & 0,94 \\
\hline
\end{tabular}

Более наглядно показано фактора «Наклон поверхности, градусы» в пределах ЛУ КП представлено на рисунке 1, где представлены гистограммы распределения. 
Гидроморфный ЛУ

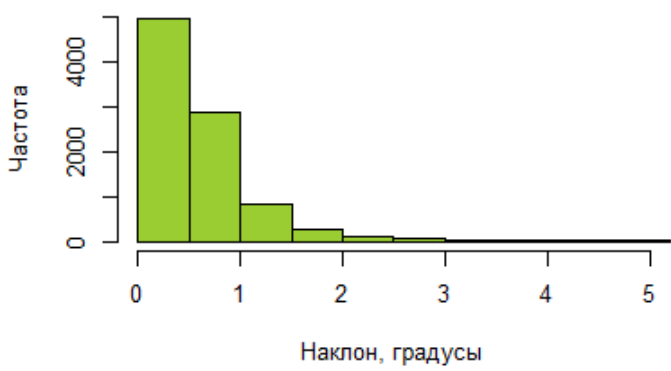

Низкогорный лу

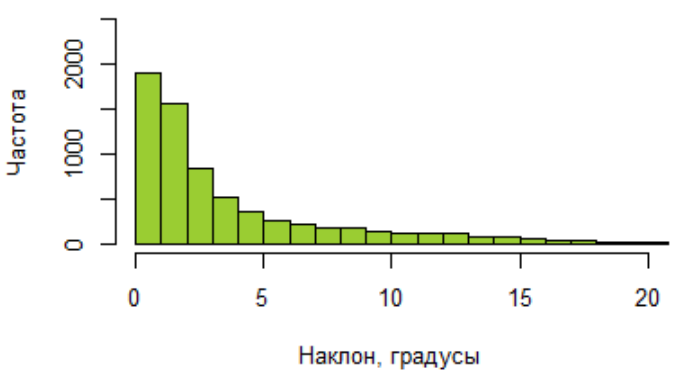

Плакорный лу

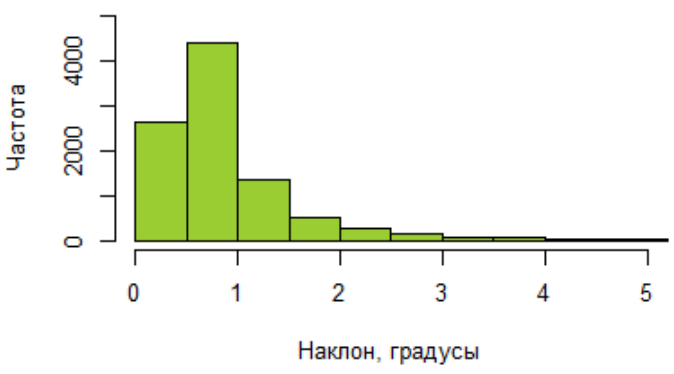

Среднегорный Лу

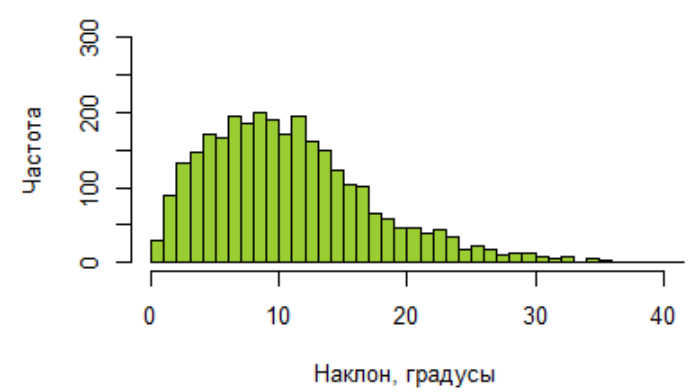

Рис. 1. Гистограммы распределения значений фактора «Наклон поверхности, градусы» в пределах ландшафтных уровней Крымского полуострова

Fig. 1. Histograms of the distribution of the values of the factor «Slope, degrees» within the landscape levels of the Crimean Peninsula

Таблица 2. Положение ландшафтных зон в пространстве фактора «Наклон поверхности, градусы»

Table 2. The position of the landscape zones of the Crimean Peninsula in the factor space «Slope, degrees»

\begin{tabular}{|c|c|c|c|c|c|c|}
\hline \multirow[b]{2}{*}{ Ландшафтная зона } & \multicolumn{5}{|c|}{ Значение фактора } & \multirow[b]{2}{*}{ 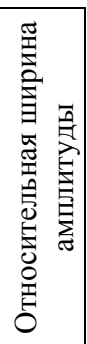 } \\
\hline & $\underset{\sum}{\sum_{i}}$ & 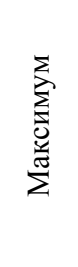 & 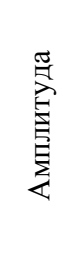 & 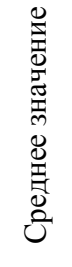 & 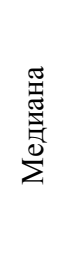 & \\
\hline \multicolumn{7}{|l|}{ Гидроморфный ландшафтный уровень } \\
\hline $\begin{array}{l}\text { Зона низменных недренированных и слабодренированных } \\
\text { аккумулятивных и денудационных равнин с типчаково-ковылковыми, } \\
\text { полынно-типчаковыми, полынно-житняковыми степями в комплексе с } \\
\text { галофитными лугами и степями }\end{array}$ & 0 & 21,7 & 21,7 & 0,7 & 0,5 & 0,33 \\
\hline \multicolumn{7}{|l|}{ Плакорный ландшафтный уровень } \\
\hline $\begin{array}{l}\text { Зона типичных ковыльно-типчаковых и бедно-разнотравно-ковыльно- } \\
\text { типчаковых степей в комплексе с петрофитными и кустарниковыми } \\
\text { степями }\end{array}$ & 0 & 17,5 & 17,5 & 1,0 & 0,7 & 0,27 \\
\hline \multicolumn{7}{|l|}{ Низкогорный ландшафтный уровень } \\
\hline $\begin{array}{l}\text { Зона предгорных аккумулятивных, останцово-денудационных и } \\
\text { структурных денудационных равнин и куэстовых возвышенностей с } \\
\text { разнотравными степями, кустарниковыми зарослями, лесостепью и } \\
\text { низкорослыми дубовыми лесами }\end{array}$ & 0 & 45,1 & 45,1 & 3,0 & 1,7 & 0,68 \\
\hline $\begin{array}{l}\text { Зона южного макросклона гор, полусубтропических дубовых, } \\
\text { фисташково-дубовых, можжевелово-сосновых лесов и шибляковых } \\
\text { зарослей }\end{array}$ & 0 & 66,1 & 66,1 & 10,8 & 10,5 & 1,00 \\
\hline \multicolumn{7}{|l|}{ Среднегорный ландшафтный уровень } \\
\hline $\begin{array}{l}\text { Зона северного макросклона гор, буковых, дубовых и смешанных } \\
\text { широколиственных лесов }\end{array}$ & 0 & 55,8 & 55,8 & 10,1 & 9,4 & 0,84 \\
\hline Зона яйлинских плато, горных лугов и горной лесостепи & 0 & 56,0 & 56,0 & 8,6 & 6,1 & 0,85 \\
\hline $\begin{array}{l}\text { Зона южного макросклона гор, дубовых, сосновых и смешанных } \\
\text { широколиственных лесов }\end{array}$ & 0,1 & 62,0 & 61,9 & 15,2 & 14,1 & 0,94 \\
\hline
\end{tabular}


1

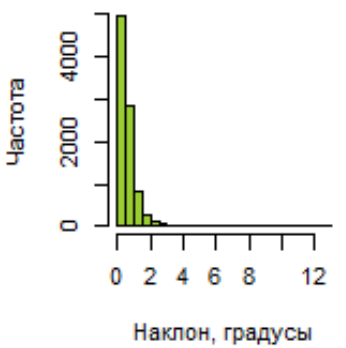

5

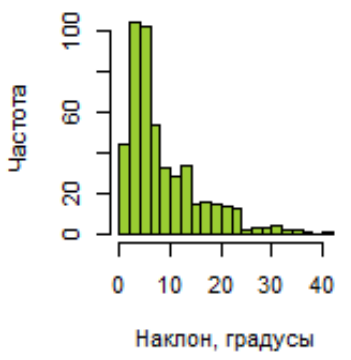

2

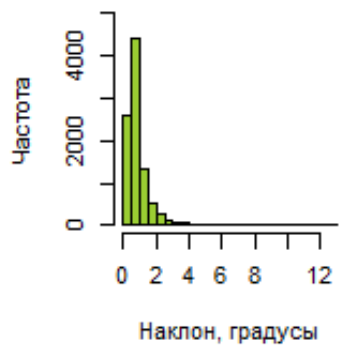

6

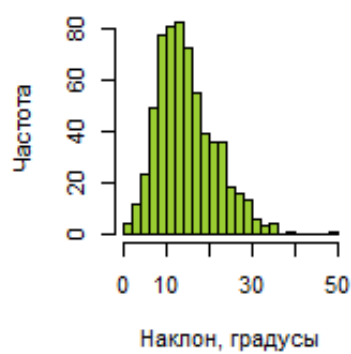

3

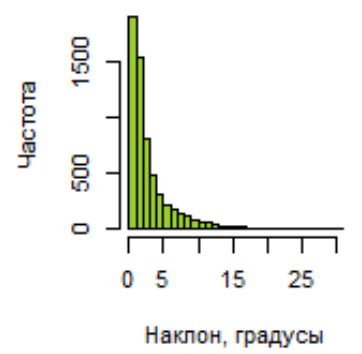

7

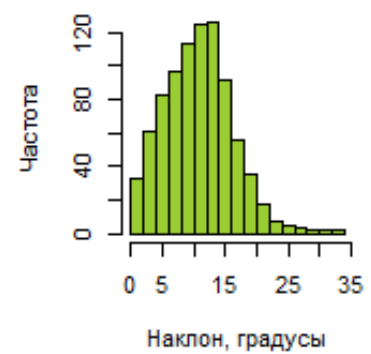

4
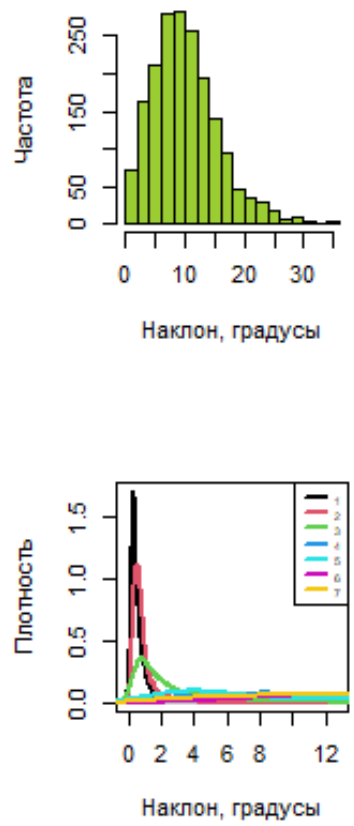

Рис. 2. Гистограммы распределения фактора «Наклон поверхности, градусы» для ландшафтных зон Крымского полуострова (цифрами обозначены ЛЗ. ГЛУ: 1 - Зона низменных недренированных и слабодренированных аккумулятивных и денудационных равнин с типчаково-ковылковыми, полынно-типчаковыми, полынно-житняковыми степями в комплексе с галофитными лугами и степями; ПЛУ: 2 - Зона типичных ковыльно-типчаковых и бедноразнотравно-ковыльно-типчаковых степей в комплексе с петрофитными и кустарниковыми степями; НЛУ: 3 - Зона предгорных аккумулятивных, останцово-денудационных и структурных денудационных равнин и куэстовых возвышенностей с разнотравными степями, кустарниковыми зарослями, лесостепью и низкорослыми дубовыми лесами;

СЛУ: 4 - Зона северного макросклона гор, буковых, дубовых и смешанных широколиственных лесов; 5 - Зона яйлинских плато, горных лугов и горной лесостепи; 6 - Зона южного макросклона гор, дубовых, сосновых и смешанных широколиственных лесов. 7 - Зона южного макросклона гор, полусубтропических дубовых, фисташково-дубовых, можжевелово-сосновых лесов и шибляковых зарослей;)

Fig. 2. Histograms of the distribution of the values of the factor «Slope, degrees» within the landscape zones of the Crimean Peninsula (numbers indicate LZ. GLU: 1 - Zone of low-lying undrained and weakly drained accumulative and denudation plains with fescue-feather grass, wormwood-fescue, wormwood-cereal steppes in a complex with halophytic meadows and steppes; and shrub steppes; NLU: 3 - Zone of foothill accumulative, remnant-denudation and structural denudation plains and cuesta uplands with forb steppes, shrub uplands with forb steppes; Zone of the northern macroslope of mountains, beech, oak and mixed broadleaved forests of the southern macro-slope; 5 - Zone mountains, oak, pine and mixed deciduous forests. 7 - Zone of the southern macroslope of mountains, semi-subtropical oak, pistachio-oak, juniper-pine forests and shibliak thickets;)

В табл. 3 представлена описательная статистика, характеризующая положение ландшафтных поясов и ландшафтных ярусов КП в пространстве фактора «Наклон поверхности, градусы». В пределах ЛП/ЛЯ ГЛУ и ПЛУ наблюдается очень слабая дифференциация, в то время как в пределах СЛУ и в меньшей степени НЛУ дифференциация ЛП проявляется отчетливо.

Учитывая тот факт, что при укрупнении уровней таксономической организации ландшафтной сферы в пределах КП, происходит увеличение объема данных описательной статистики, то для групп местностей КП результаты описательной статистики представлены в виде картографических материалов (рис. 3).

Как видно из рисунка 3 по рассматриваемому фактору внутри групп местностей в пределах ЛП и ЛЯ и более высоких уровней таксономической организации ландшафтной сферы наблюдается незначительные различия рассматриваемого показателя, которое увеличивается при сравнении групп местностей, относящихся к более высоким уровням таксономической организации.

Учитывая тот факт, что во многих работах, о которых пойдет речь в дальнейшем, термины «наклон», «крутизна» или «крутизна склонов» и «уклон» не отличаются и результаты измерений приводятся в градусах, здесь мы будем использовать их как синонимы, что, однако, не совсем верно. Такая путаница возникает, особенно среди специалистов, использующих ГИС при выполнении исследований, так как инструмент для расчета в программе ArcGIS русифицирован именно как «Уклон», а в QGIS - как «Крутизна». 
Таблица 3. Положение ландшафтных поясов и ландшафтных ярусов Крымского полуострова в пространстве фактора «Наклон поверхности, градусы»

Table 3. The position of the landscape layers of the Crimean Peninsula in the factor space «Slope, degrees»

\begin{tabular}{|c|c|c|c|c|c|c|}
\hline \multirow[b]{2}{*}{ Ландшафтный пояс / ярус } & \multicolumn{5}{|c|}{ Значение фактора } & \multirow[b]{2}{*}{ 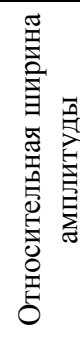 } \\
\hline & $\sum_{\sum}^{\sum}$ & 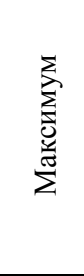 & 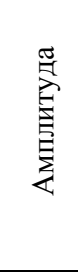 & 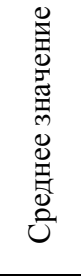 & 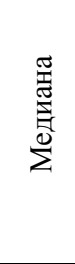 & \\
\hline \multicolumn{7}{|c|}{ Гидроморфный ландшафтный уровень } \\
\hline $\begin{array}{l}\text { Пояс прибрежных недренированных низменностей, пляжей и кос с } \\
\text { галофитными лугами, солончаками и сообществами псаммофитов }\end{array}$ & 0 & 55,8 & 55,8 & 10,1 & 9,4 & 0,84 \\
\hline $\begin{array}{l}\text { Пояс аккумулятивных и денудационных недренированных и } \\
\text { слабодренированных низменностей с полынно-типчаковыми, полынно- } \\
\text { житняковыми и ковыльно-типчаковыми степями }\end{array}$ & 0 & 56,0 & 56,0 & 8,6 & 6,1 & 0,85 \\
\hline $\begin{array}{l}\text { Пояс аккумулятивных и денудационных слабодренированных равнин с } \\
\text { ковыльно-типчаковыми и полынно-типчаковыми степями }\end{array}$ & 0,1 & 62,0 & 61,9 & 15,2 & 14,1 & 0,94 \\
\hline $\begin{array}{l}\text { Пояс аккумулятивных дренированных и слабодренированных } \\
\text { низменностей с ковыльно-типчаковыми степями в комплексе с } \\
\text { ковыльно-разнотравными степями }\end{array}$ & 0 & 55,8 & 55,8 & 10,1 & 9,4 & 0,84 \\
\hline \multicolumn{7}{|l|}{ Плакорный ландшафтный уровень } \\
\hline $\begin{array}{l}\text { Верхний денудационный ярус ковыльно-типчаковых, петрофитных и } \\
\text { кустарниковых степей }\end{array}$ & 0 & 17,5 & 17,5 & 1,1 & 0,7 & 0,27 \\
\hline $\begin{array}{l}\text { Нижний денудационно-аккумулятивный ярус с ковыльно- } \\
\text { типчаковыми, кустарниково-разнотравными и петрофитными степями }\end{array}$ & 0 & 15,5 & 15,5 & 0,9 & 0,7 & 0,23 \\
\hline \multicolumn{7}{|c|}{ Низкогорный ландшафтный уровень } \\
\hline \multicolumn{7}{|c|}{$\begin{array}{c}\text { Зона предгорных аккумулятивных, останцово-денудационных и структурных денудационных равнин и куэстовых } \\
\text { возвышенностей с разнотравными степями, кустарниковыми зарослями, лесостепью и низкорослыми дубовыми } \\
\text { лесами }\end{array}$} \\
\hline $\begin{array}{l}\text { Пояс бородачево-разнотраных и асфоделиново-разнотравных степей на } \\
\text { аккумулятивных и денудационных равнинах }\end{array}$ & 0 & 14,6 & 14,6 & 1,3 & 0,9 & 0,22 \\
\hline $\begin{array}{l}\text { Пояс лесостепи на останцово-денудационных, структурных } \\
\text { денудационных и аккумулятивных равнинах, куэстовых } \\
\text { возвышенностях }\end{array}$ & 0 & 45,1 & 45,1 & 3,9 & 2,9 & 0,68 \\
\hline $\begin{array}{l}\text { Пояс дубовых лесов и кустарниковых зарослей на останцово- } \\
\text { денудационных и наклонных структурных денудационных равнинах и } \\
\text { куэстовых возвышенностях }\end{array}$ & 0 & 44,4 & 44,4 & 9,1 & 7,9 & 0,67 \\
\hline \multicolumn{7}{|l|}{ Среднегорный ландшафтный уровень } \\
\hline \multicolumn{7}{|c|}{ Зона северного макросклона гор, буковых, дубовых и смешанных широколиственных лесов } \\
\hline $\begin{array}{l}\text { Пояс котловин и эрозионного низкогорья, дубовых, смешанных } \\
\text { широколиственных и сосновых лесов }\end{array}$ & 0 & 44,8 & 44,8 & 8,5 & 8,1 & 0,68 \\
\hline $\begin{array}{l}\text { Пояс среднегорно-склоновый, дубовых, можжевелово-дубовых и } \\
\text { смешанных широколиственных лесов }\end{array}$ & 0 & 44,4 & 44,4 & 10,8 & 10,2 & 0,67 \\
\hline $\begin{array}{l}\text { Пояс среднегорно-склоновый, буковых, буково-грабовых, смешанных } \\
\text { широколиственных лесов }\end{array}$ & 0 & 55,8 & 55,8 & 14,4 & 13,7 & 0,84 \\
\hline \multicolumn{7}{|c|}{ Зона яйлинских плато, горных лугов и горной лесостепи } \\
\hline Пояс лесных и лугово-лесостепных плато & 0 & 56,0 & 56,0 & 7,2 & 5,0 & 0,85 \\
\hline Пояс луговых и лугово-лесных плато & 0,13 & 49,3 & 49,2 & 12,2 & 10,2 & 0,74 \\
\hline \multicolumn{7}{|c|}{$\begin{array}{c}\text { Зона южного макросклона гор, дубовых, сосновых и } \\
\text { смешанных широколиственных лесов }\end{array}$} \\
\hline $\begin{array}{l}\text { Пояс низкогорно-склоновый дубовых и смешанных широколиственных } \\
\text { лесов }\end{array}$ & 0,13 & 37,5 & 37,4 & 12,9 & 12,8 & 0,57 \\
\hline $\begin{array}{l}\text { Пояс среднегорно-склоновый, дубовых, сосновых и смешанных } \\
\text { широколиственных лесов }\end{array}$ & 0,18 & 57,5 & 57,3 & 16,7 & 14,9 & 0,87 \\
\hline Среднегорный пояс буковых и смешанных широколиственных лесов & 0,13 & 62,0 & 61,9 & 18,8 & 17,7 & 0,94 \\
\hline \multicolumn{7}{|c|}{ Низкогорный ландшафтный уровень } \\
\hline \multicolumn{7}{|c|}{$\begin{array}{c}\text { Зона южного макросклона гор, полусубтропических дубовых, фисташково-дубовых, можжевелово-сосновых лесов } \\
\text { и шибляковых зарослей }\end{array}$} \\
\hline $\begin{array}{l}\text { Низкогорный пояс дубово-фисташковых, можжевелово-сосновых лесов } \\
\text { и шибляковых зарослей }\end{array}$ & 0 & 66,1 & 66,1 & 10,7 & 10,2 & 1,00 \\
\hline $\begin{array}{l}\text { Низкогорный пояс сосновых, дубовых и смешанных } \\
\text { широколиственных лесов и шибляковых зарослей }\end{array}$ & 0 & 53,5 & 53,5 & 11,1 & 10,9 & 0,81 \\
\hline
\end{tabular}




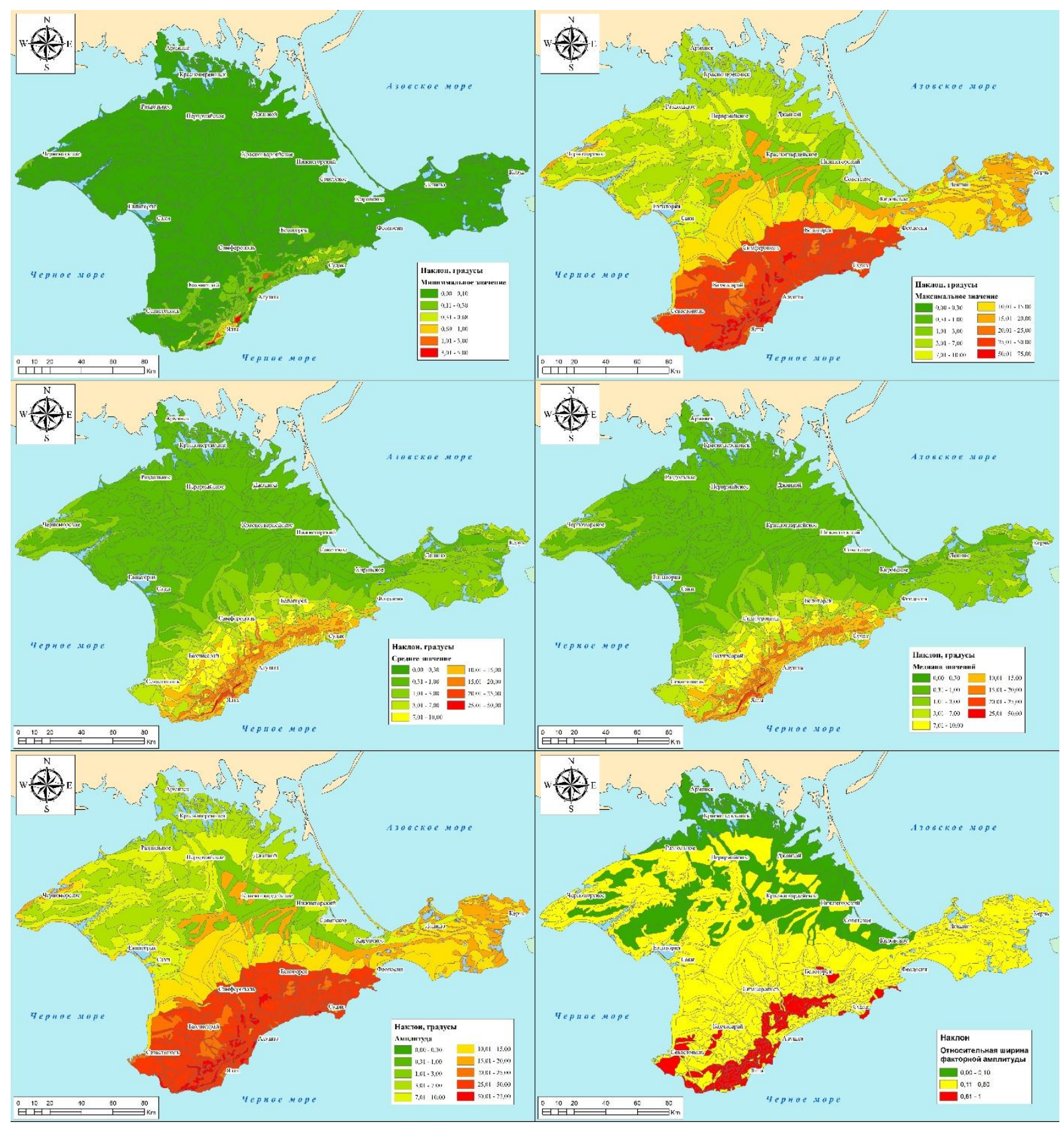

Рис. 3. Положение групп местностей в пространстве фактора «Наклон поверхности, градусы».

Fig. 3. The position of groups of localities in the factor space «Slope, degrees».

Разрозненные сведения о наклоне поверхности для территории КП и в большей степени его отдельных частей приводятся в работах $[24,25]$. Стоит с акцентировать внимание на том факте, что изучению именно крутизны склонов или наклона поверхности в пределах ландшафтов Крымского полуострова практически не уделяется внимание, поэтому возникают большие сложности с сравнением полученных результатов.

Ф.Н. Лисецкий с соавторами в работе [10, С. 39 40] приводит значение наклона поверхности для территории Тарханкутского полуострова и указывают, что для Южнотарханкутского увала характерны значения наклона поверхности от 1,5 до 3 градусов, для северной части полуострова в районе урочищ Джангуль, Большой Кастель, Малый
Кастель, а также отдельных участков вдоль побережья - характерны максимальные значения более 3 градусов. Стоит отметить, что на карте в [10, С. 40] не приводится максимальные значения наклона поверхности (крутизны склонов) для территории Тарханкутского полуострова, а ограничиваются только формулировкой более 3 -х градусов. Если сравнивать с нашими данными, то в пределах Южнотарханкутского увала располагаются ландшафтные контура входящие в группу местностей «наклонные овражно-балочные равнины с ковыльно-типчаковыми, петрофитными и кустарниковыми степями» то здесь максимальный наклон поверхности составляет 7,7 градуса, а среднее значение - 1,7 градуса. В пределах севернозападной части Тарханкутского полуострова 
располагается группа местностей, представленная одним ландшафтным контуром - «овражнобалочный оползневой ковыльно-типчаковых и кустарниково-разнотравных степей», для которого характерны максимальное значение составляет 15,5 градуса, а среднее - 3,3 градуса. Таким образом данные представленные в [10] косвенно подтверждают полученные нами результаты.

В работе [26] Д.О. Кривогуз с соавторами приводятся карту уклонов КП, на которой градация этого фактора изменяется от 0 до 90 градусов. По нашим данным значения наклона поверхности для КП изменяются от 0 до 66,1 градуса. Эти данные также подтверждаются в работах $[2,3]$. В виду того, что в работе [26, С. 8] карта уклонов имеет очень мелкий масштаб и к тому же легенда к этой карте представлена в виде растяжки, а не картограммы, то невозможно провести сравнение с результатами, полученными в этой работе.

В работе [27] указывается, что на территории Керченского полуострова максимальные значения наклона составляют более 40 градусов и на этот диапазон действия фактора приходится 107,7 кв. км территории Керченского полуострова, что составляет около 4 \% от его площади. Эти данные значительно противоречат нашим расчетным данным о наклоне поверхности на территории Керченского полуострова. Так по нашим расчетам максимальный наклон поверхности среди групп местностей Керченского полуострова составляет примерно 15-17 градусов и характерен для таких групп местностей: абразионно-денудационные останцовые равнины с кустарниковыми разнотравными степями абразионноденудационные останцовые равнины с ковыльнотипчаковыми и петрофитными степями; пологонаклонные аккумулятивно-денудационные лессовидные равнины с ковыльно-типчаковыми и ковыльно-разнотравными степями; денудационноостанцовые равнины с типчаково-ковыльными степями. К тому же, данные полученные в [27] являются завышенными. Это различие может быть объяснено различными исходными данными, которые использовались. Так в нашей работе были использованы цифровые модели рельефа SRTM, а в работе [27] - ASTER GDEM.

В работе [28, С. 206] указывается, что в Горном Крыму крутизна склонов составляет 5-10 градусов, что является значительно заниженным значением, ведь Горный Крым - характеризуется максимальными значениями крутизны склонов и по нашим расчетам, если принимать за Горный Крым территории НЛУ и СЛУ крутизна склонов здесь составляет более 60 градусов. В тоже время указанные в работе [28, С. 206] значения похожи на средние значения по НЛУ и СЛУ (4,0 и 10,9 градуса) рассчитанные нами. Так как в [28] не указывается методика исследования и неясно откуда получены данные, то вероятнее всего можно принять их за средние данные по Горному Крыму.

В работе [29] И.В. Калинчук и Е.А. Позаченюк произвели расчеты средних значений крутизны склонов в пределах ландшафтных выделов Раздольненского района Республики Крым. Сравнение наших данных и данных, представленных в работе [29], указывает на их сопоставимость. Например, среднее значение наклона поверхности в пределах группы местностей № 1 - аккумулятивные недренированные низменности с солончаками и галофитными лугами - согласно [29] составляет 0,31-0,51 градуса, в виду того, что в работе [29] анализируется каждый контур, слагающий группу местностей; а по нашим расчетам - среднее значение в пределах группы местностей - 0,71 градуса, а в пределах двух ландшафтных контуров слагающих группу местностей в Раздольненском районе Республики Крым - 0,28 и 0,40 градуса. Более развернутое сравнение полученных нами данных с работой [29] представлено в таблице 4 .

Таблица 4. Наклон поверхности некоторых ландшафтных контуров групп местностей Крымского полуострова в пределах Раздольненского района Республики Крым

Table 4. The slope of the surface of some landscape contours of groups of localities of the Crimean Peninsula within the Razdolnensky district of the Republic of Crimea

\begin{tabular}{|l|c|c|}
\hline Ландшафтный контур / Группа местностей & \multicolumn{2}{|c|}{ Наклон поверхности, градусы } \\
\cline { 2 - 3 } & Среднее значение & $\begin{array}{l}\text { Среднее значение, } \\
\text { по [29] }\end{array}$ \\
\hline $\begin{array}{l}\text { Пересыпи и косы с галофитными лугами в комплексе с сообществами } \\
\text { псаммофитов }\end{array}$ & 0,34 & 0,38 \\
\hline $\begin{array}{l}\text { Аккумулятивные плоские слабодренированные равнины с полынно- } \\
\text { житняковыми и ковылково-типчаковыми степями }\end{array}$ & 0,32 & 0,48 \\
\hline Долинно-лощинно-балочный, лугов и луговых степей & 0,74 & 0,82 \\
\hline $\begin{array}{l}\text { Структурные пологонаклонные денудационно-аккумулятивные равнины с } \\
\text { ковыльно-типчаковыми степями }\end{array}$ & 0,72 & 0,78 \\
\hline
\end{tabular}

Таким образом, можно говорить о том, что полученные данные о наклоне поверхности в пределах групп местностей для КП частично подтверждается работами [29, 30].

В целом, можно утверждать, что полученные данные репрезентативны, частично подтверждаются независимыми работами исследователей и на данный момент дает полную характеристику положения таксономических единиц ландшафтной сферы для КП. 


\section{ВЫВОДЫ}

В работе впервые для ландшафтных единиц организации территории Крымского полуострова (ландшафтные уровни, ландшафтные зоны, ландшафтные пояса и ярусы, а также группы местностей) рассчитаны и получены репрезентативные данные о минимальных, максимальных, средних значениях, амплитуде значений и медиане значений наклона поверхности в пределах таксономических единиц ландшафтной организации. Установлено, что максимальные значения наклона поверхности характерны для низкогорного и среднегорного ландшафтных уровней Крымского полуострова, а минимальные для гидроморфного ландшафтного уровня.

Исследование выполнено в рамках темы НИР «Изучение пространственно-временной организации водных и сухопутных экосистем $c$ целью развития системы оперативного мониторинга на основе данных дистаниионного зондирования и ГИС-технологий. Регистраџионный номер: 121040100327-3».

\section{СПИСОК ЛИТЕРАТУРЫ}

1. Позаченюк Е.А., Панкеева Т.В. Геоэкологическая экспертиза административных территорий. Большой Севастополь. Симферополь: Бизнес-Информ, 2008. 296 с.

2. Пурдик Л.Н. Ландшафтный подход в территориальном планировании (на примере Беловского района Кемеровской области). Барнаул : Пять плюс, 2012. 191 с.

3. Позаченюк Е.А., Табунщик В.А. Ландшафтное планирование территории Джанкойского района Республики Крым // Ученые записки Крымского федерального университета имени В.И. Вернадского. География. Геология. 2014. №2. C. $139-162$.

4. Позаченюк Е.А., Петлюкова Е.А., Табунщик В.А. Понятие «современный ландшафт» и организация природопользования (на примере водоохранных зон) // Ученые записки Таврического национального университета имени В.И. Вернадского. Серия: География. 2013. Т.26(65). №3. C. 299-309.

5. Клюкин А.А. Экзогеодинамика Крыма. Симферополь: Таврия, 2007. 320 с.

6. Подгородецкий П.Д. Крым: природа. Симферополь: Таврия, 1988. 192 с.

7. Вахрушев Б. А., Ковальчук И. П., Комлев А. А. и др. Рельеф Украины / Под ред. В. В. Стецюка. Киев: Слово, 2010. 688 с.

8. Бондаренко М.А., Михайлов В.А. Геоморфологические факторы формирования высотной поясности растительного покрова юговосточного склона Бабуган-яйлы (Крымский полуостров) // Современные научные исследования и инновации. 2016. № 7 (63). С. 295-301.
9. Михайлов В.А. Комплексный морфометрический анализ Тарханкутского полуострова с помощью ГИС // Современные научные исследования и инновации. 2015. № 2-4 (46). C. 5-13.

10. Лисецкий Ф.Н., Маринина О. А., Буряк Ж.А. Геоархеологические исследования исторических ландшафтов Крыма. Воронеж : ВГУ, 2017. 431 с.

11. Позаченюк Е.А., Петлюкова Е.А. ГИС-анализ морфометрических показателей рельефа Центрального Предгорья Главной гряды Крымских гор для целей ландшафтного планирования // Ученые записки Крымского федерального университета имени В.И Вернадского. География. Геология. 2016. Т. 2 (68). № 2. С. 96-113.

12. Атлас природных условий и естественных ресурсов Украинской ССР / АН УССР. Москва : Главное управление геодезии и картографии при Совете Министров СССР, 1978. 183 с.

13. Національний атлас України / голов. ред. Л. Г. Руденко; голова ред. кол. Б.С. Патон. Київ: Картографія, 2007. 435 с.

14. Автономна Республіка Крим: атлас / ТНУ ім. В.I. Вернадського, Крим. наук.центр НАН України і М-ва освіти і науки України, Ін-т географії НАН України, Ін-т перед. технологій ; ред. М.В. Багров [та ін.]. К. ; Симферополь: ТНУ, 2003. 76 с.

15. Sreedevi P. D. et al. Morphometric analysis of a watershed of South India using SRTM data and GIS //Journal of the geological society of india. 2009. Vol. 73. №. 4. pp. 543-552. DOI 10.1007/s12594-009-00384.

16. Yang G., Chen Z., Jiang J. Drainage morphometry of the Lishui catchment in the middle Yangtze basin, China: morphologic and tectonic implications //Arabian Journal of Geosciences. 2020. Vol. 13. №. 13. pp. 1-14. DOI10.1007/s12517-02005481-w

17. Kramm T., Hoffmeister D. A relief dependent evaluation of digital elevation models on different scales for northern Chile //ISPRS International Journal of GeoInformation. 2019. Vol. 8. №. 10. pp. 430. DOI 10.3390/ijgi8100430

18. Ashatkin I.A. et al. Analysis of Relief Morphometry by Global DEM in the Southern Part of the European Territory of Russia // Uchenye Zapiski Kazanskogo Universiteta. Seriya Estestvennye Nauki. 2020. Vol. 162. № 4. pp. 612-628. DOI 10.26907/2542064X.2020.4.612-628

19. Tarikhazer S. A. Morphometric Analysis of the Relief of the North-Eastern Slope of the Great Caucasus for the Purpose of Tourism Potential (using GIS technologies) // News of the National Academy of Sciences of the Republic of Kazakhstan. Series of Geology and Technical Sciences. 2020. №. 2. pp. 170177. DOI 10.32014/2020.2518-170X.45

20. Современные ландшафты Крыма и сопредельных акваторий / Е.А. Позаченюк, В.М. Шумский, А.М. Лесов [и др.]; Республиканский комитет Автономной республики Крым по охране окружающей природной среды Таврический национальный университет имени В.И. 
Вернадского. Симферополь: Бизнес-Информ, 2009. $672 \mathrm{c.}$

21. Табунщик, В.А. Крутизна склонов в пределах ландшафтных уровней Крымского полуострова / В.А. Табунщик // Материалы региональной научнопрактической конференции студентов, аспирантов и молодых учёных по естественным наукам : Научное электронное издание, Владивосток, 16-30 апреля 2018 года. Владивосток: Дальневосточный федеральный университет, 2018. С. 62-64.

22. Табунщик, В.А. Построение карты крутизны склонов Крымского полуострова с использованием программных комплексов ArcGIS и Quantum GIS (QGIS) / В.А. Табунщик // Дни науки КФУ им. В.И. Вернадского: Сборник тезисов участников IV научно-практической конференции профессорскопреподавательского состава, аспирантов, студентов и молодых ученых, Симферополь, 12-17 октября 2018 года. Симферополь: Крымский федеральный университет им. В.И. Вернадского, 2018. С. 12191220.

23. Гродзинський М.Д., Свідзінська Д.В. Ніші ландшафтів України у просторі кліматичних факторів. Київ: Обрії, 2008. 259 с.

24. Иванченко, В. И. Влияние крутизны склона на агробиологические показатели виноградного сорта Мускат белый в условиях Южного берега Крыма / В. И. Иванченко, О. Г. Замета, В. А. Мельников // Магарач. Виноградарство и виноделие. 2015. № 2. С. 19-21.

25. Иванченко, В.И. Характеристика пространственного распределения агроэкологических ресурсов филиала "Таврида" ФГУП "ПАО "Массандра" // Известия сельскохозяйственной науки Тавриды. 2016. № 5(168). С. 31-40.

26. Кривогуз, Д.О. Применение ГИС для определения оползневой устойчивости Крымского полуострова / Д.О. Кривогуз, С.В. Малько, А.Ю. Семенова // Геоинформатика. 2016. № 3. С. 3-11.

27. Krivoguz, D. Landslide susceptibility analysis for the Kerch Peninsula using weights of evidence approach and GIS / D. Krivoguz, L. Bespalova // Russian Journal of Earth Sciences. 2020. Vol. 20. № 1. P. 1003. DOI 10.2205/2020ES000682.

28. Пахомова, О.М. Оценка ландшафтногеоморфологических условий горного Крыма для целей рекреации и туризма // Проблемы и перспективы развития туризма в Южном федеральном округе: Сборник научных трудов, Севастополь, 11-14 октября 2017 года. Севастополь: Общество с ограниченной ответственностью «Издательство Типография «Ариал», 2017. С. 205207.

29. Калинчук И.В. Оценка степени коадаптации агроландшафтов Раздольненского района Республики Крым // Геополитика и экогеодинамика регионов. 2016. Т. 2 (12). № 4. С. 13-30.

30. Калинчук И.В. Оценка степени коадаптации агроландшафтов Раздольненского района Республики Крым // Ученые записки Крымского федерального университета имени В.И
Вернадского. География. Геология. 2017. Т. 3 (69). № 2. C. 84-101.

\section{REFERENCES}

1. Pozachenyuk E.A., Pankeeva T.V. Geoecological examination of administrative territories. Bolshoy Sevastopol. Simferopol: Business-Inform, 2008. 296 p.

2. Purdik, L.N. Landscape approach in territorial planning (on the example of the Belovsky district of the Kemerovo region). Barnaul : Piat Plus, 2012. 191 p.

3. Pozachenyuk E.A., Tabunshchik V.A. Landscape Planning Area of Dzhankoysky Region of Republic of Crimea // Scientific notes of the Crimean Federal University named after V.I. Vernadsky. Geography. Geology. 2014. No. 2. pp. 139-162. (In Russian)

4. Pozachenyuk E.A., Petlyukova E.A., Tabunshchik V. A. The concept of "modern landscape" and the organization of nature management (on the example of water protection zones) / / Scientific notes of the Tauride National University named after V.I. Vernadsky. Series: Geography. 2013. Vol.26(65). No3. pp. 299-309. (In Russian)

5. Klyukin A. A. Exogeodynamics of the Crimea. Simferopol: Tavria, 2007. 320 p.

6. Podgorodetsky P. D. Crimea: nature. Simferopol: Tavria, 1988. $192 \mathrm{p}$.

7. Vakhrushev B.A., Kovalchuk I.P., Komlev A.A., etc. Relief of Ukraine / Edited by V.V. Stetsyuk. Kiev: Slovo, 2010. 688 p.

8. Bondarenko M.A., Mikhailov V.A. Geomorphological factors of the formation of the highaltitude zone of the vegetation cover of the south-eastern slope of Babugan-yayly (Crimean Peninsula) / / Modern scientific research and innovations. 2016. No. 7 (63). pp. 295-301. (In Russian)

9. Mikhailov V.A. Complex morphometric analysis of the Tarkhankut peninsula using GIS // Modern scientific research and innovations. 2015. No. 2-4 (46). pp. 5-13. (In Russian)

10. Lisetsky F.N., Marinina O.A., Buryak Zh. A.A geoarcheological survey of the historical landscapes of Crimea. Voronezh : VSU, 2017. 431 p.

11. Pozachenyuk E.A., Petlyukova E.A. GISanalysis of morphometric indicators of the relief of the Central Foothills of the Main ridge of the Crimean Mountains for the purposes of landscape planning / / Scientific notes of the V.I. Vernadsky Crimean Federal University. Geography. Geology. 2016. Vol. 2(68). No2. pp. 96-113. (In Russian)

12. Atlas of natural conditions and natural resources of the Ukrainian SSR / AS of the Ukrainian SSR. Moscow: Main Directorate of Geodesy and Cartography under the Council of Ministers of the USSR, 1978. $183 \mathrm{p}$.

13. National Atlas of Ukraine / head. ed. L.G. Rudenko; head. ed. Col. B.E. Paton. Kiev: Kartografiya, 2007. 435 p.

14. Autonomous Republic of Krim: atlas / TNU im. V.I. Vernadsky, Krim. nauk.Center of the National Academy of Sciences of Ukraine i M-va osviti i sciences of Ukraine, In-t geography of the National Academy of 
Sciences of Ukraine, In-t before. technologii; ed. M. V. Bagrov [ta in.]. K.; Simferopol: TNU, 2003. 76 p.

15. Sreedevi P.D. et al. Morphometric analysis of a watershed of South India using SRTM data and GIS //Journal of the geological society of india. 2009. Vol. 73. №. 4. pp. 543-552. DOI 10.1007/s12594-009-00384

16. Yang G., Chen Z., Jiang J. Drainage morphometry of the Lishui catchment in the middle Yangtze basin, China: morphologic and tectonic implications //Arabian Journal of Geosciences. 2020. Vol.13. №13. pp. 1-14. DOI10.1007/s12517-02005481-w

17. Kramm T., Hoffmeister D. A relief dependent evaluation of digital elevation models on different scales for northern Chile //ISPRS International Journal of GeoInformation. 2019. Vol.8. №10. pp. 430. DOI 10.3390/ijgi8100430

18. Ashatkin I.A. et al. Analysis of Relief Morphometry by Global DEM in the Southern Part of the European Territory of Russia // Uchenye Zapiski Kazanskogo Universiteta. Seriya Estestvennye Nauki. 2020. Vol. 162. No. 4. pp. 612-628. DOI 10.26907/2542-064X. 2020.4.612-628

19. Tarikhazer S.A. Morphometric Analysis of the Relief of the North-Eastern Slope of the Great Caucasus for the Purpose of Tourism Potential (using GIS technologies) // News of the National Academy of Sciences of the Republic of Kazakhstan. Series of Geology and Technical Sciences. 2020. №. 2. pp. 170177. DOI 10.32014/2020.2518-170X.45

20. Modern landscapes of the Crimea and adjacent water areas / E.A. Pozachenyuk, V.M. Shumsky, A.M. Lesov [et al.]; Republican Committee of the Autonomous Republic of Crimea for Environmental Protection of the Tauride National University named after V.I. Vernadsky. Simferopol: Business-Inform, 2009. $672 \mathrm{p}$.

21. Tabunshchik, V.A. The steepness of slopes within the landscape levels of the Crimean Peninsula / V.A. Tabunshchik / / Materials of the regional scientific and practical conference of students, postgraduates and young scientists in natural sciences: Scientific electronic edition, Vladivostok, April 16-30, 2018. Vladivostok: Far Eastern Federal University, 2018. pp. 62-64. (In Russian)

22. Tabunshchik, V.A. Constructing a map of the steepness of the slopes of the Crimean peninsula using the software complexes ArcGIS and Quantum GIS (QGIS) // Days of Science of the V. I. Vernadsky KFU:
A collection of abstracts of participants of the IV scientific and practical conference of the teaching staff, graduate students, students and young scientists, Simferopol, October 12-17, 2018. Simferopol: V.I. Vernadsky Crimean Federal University, 2018. pp. 1219-1220. (In Russian)

23. Grodzinsky M.D., Svidzinka D.V. Nishi landscape of Ukraine at the spacious climatic factors. Kiev: Obri, 2008. 259 p.

24. Ivanchenko, V.I. The influence of slope steepness on agrobiological indicators of the white Muscat grape variety in the conditions of the Southern coast of the Crimea / V.I. Ivanchenko, O.G. Zameta, V.A. Melnikov // Magarach. Viticulture and winemaking. 2015. No. 2. pp. 19-21. (In Russian)

25. Ivanchenko, V.I. Characteristics of the spatial distribution of agroecological resources of the branch "Tavrida" of FSUE "PAO "Massandra" / / Izvestiya agraricheskoi nauki Tavrida. 2016. No. 5(168). pp. 3140.

26. Krivoguz, D.O. Application of GIS for determining the landslide stability of the Crimean peninsula / D.O. Krivoguz, S.V. Malko, A.Yu. Semenova // Geoinformatics. 2016. No. 3. pp. 3-11. (In Russian)

27. Krivoguz, D. Landslide susceptibility analysis for the Kerch Peninsula using weights of evidence approach and GIS / D. Krivoguz, L. Bespalova // Russian Journal of Earth Sciences. 2020. Vol. 20. № 1. P. 1003. DOI 10.2205/2020ES000682. (In Russian)

28. Pakhomova, O.M. Assessment of landscapegeomorphological conditions of the mountainous Crimea for the purposes of recreation and tourism // Problems and prospects of tourism development in the Southern Federal District: Collection of scientific papers, Sevastopol, October 11-14, 2017. Sevastopol: Limited Liability Company " Publishing House Printing House "Arial", 2017. pp. 205-207. (In Russian)

29. Kalinchuk I.V. Assessment of the degree of coadaptation of agricultural landscapes of the Razdolnensky district of the Republic of Crimea // Geopolitics and ecogeodynamics of regions. 2016. Vol.2(12). No4. pp. 13-30. (In Russian)

30. Kalinchuk I.V. Assessment of the degree of coadaptation of agricultural landscapes of the Razdolnensky district of the Republic of Crimea // Scientific notes of the V.I. Vernadsky Crimean Federal University. Geography. Geology. 2017. Vol.3(69). No2. pp. 84-101. (In Russian) 


\title{
SPATIAL DISTRIBUTION OF THE SURFACE SLOPE WITHIN THE LANDSCAPES OF THE CRIMEAN PENINSULA
}

\author{
Tabunshchik V.A.
}

A.O. Kovalevsky Institute of Biology of the Southern Seas of RAS (IBSS), 299011, 2 Nakhimov Avenue, Sevastopol, Russia

\begin{abstract}
The paper presents new data on the slope of the surface of the territory of the Crimean Peninsula in the context of landscape taxonomic units according to the landscape-typological map of the Crimean polostrov by G. E. Grishankov. For the first time, for the Crimean Peninsula as a whole and landscape taxonomic units - landscape levels, landscape zones, landscape belts and tiers, as well as groups of localities (okoems), elements of descriptive statistics (minimum value, maximum value, average value, median value, as well as the value of the amplitude of values (factor amplitude)) that characterize the slope of the surface within the specified territories are quantitatively calculated.

Subject: geomorphological features of the slope of the surface within the territory of the Crimean Peninsula, in particular, landscapes at various taxonomic levels due to the weak elaboration of this issue.

Materials and methods: The paper uses a digital terrain model SRTM on the basis of which maps of the slope of the surface for the territory of the Crimean Peninsula and the landscapes of the Crimean Peninsula are constructed. The processing was performed in the ArcGIS software package. Geospatial models (geo-linked raster and vector layers) are used in the work, which allow performing SQL queries and analyzing the spatial position of research objects. The research methods are literary-analytical, historical, comparative-geographical, geoinformation, statistical, as well as the modeling method.

Results: for the first time, new data on the values of the surface slope within various hierarchical levels of the landscape structure of the Crimean Peninsula were obtained.

Conclusions: the slope of the surface within the landscape contours for the territory of the Crimean Peninsula is characterized by significant spatial heterogeneity-it increases from north to south and reaches maximum values within the mid-mountain and lowmountain landscape levels, and minimum values-within the hydromorphic landscape level.
\end{abstract}

Key words: relief, surface slope, Crimea, Crimean Peninsula, landscape. 